\title{
Durability of Concrete as a Function of the Properties of the Concrete Layer
}

\section{J. Adámek}

Department of Building Testing, Faculty of Civil Engineering, Brno University of Technology, Czech Republic

*Corresponding author: adamek.j@fce.vutbr.cz

V. Juránková

Department of Physics, Faculty of Civil Engineering, Brno University of Technology, Czech Republic

\begin{abstract}
The changes that the properties of construction materials undergo during this period are extremely difficult to keep track of, and the same holds for the assessment of the causes their degradation. One of the current diagnostic methods to evaluate the actual state of the concrete surface layers is the structure air permeability method. The method was developed theoretically by J.R.Torrent, who also assisted in the manufacturing of an excellent device, the TPT (torrent Permeability Tester). It is a relatively new, nondestructive method, applicable both in the laboratory and on construction sites. This paper will describe the test results from application of different admixture on the air permeability of concrete surface layers.
\end{abstract}

KEYWORDS: Concrete, air permeability, moisture, durability.

\section{INTRODUCTION}

Concrete is a heterogeneous material consisting of aggregates bound with cement paste. Its performance properties are thus influenced by the properties of its constituent materials, itsmixing, placement and curing, and its environmental exposure. It is an established fact that differences in relative humidity and temperature in both the curing and storage conditions result in noticeable variations in concrete properties due to the fact that environmental exposure determines the moisture content and moisture distribution in a concrete specimen. Thus, the determination of the moisture content of test specimens at the time of testing is vital for the correct interpretation of test results.

It has been generally understood that in the study of the durability properties of concrete, the topmost concrete cover, which is about $30-50 \mathrm{~mm}$, requires more attention than the inner section, since nearly all transport mechanisms in concrete are influenced by the quality of this layer. Consequently, the gas permeability measurement of concrete cover is considered to be more suitable in assessing the performance properties of concrete than diffusivity, sorptivity or water permeability measurements for various reasons: e.g. gas permeability values are more sensitive to changes in the pore structure; gas permeability measurements are relatively simple, take only a short time, and produce repeatable test results. In this respect, the tendencies of current research work are aimed at relating measured gas 
permeability coefficients of concrete to the performance properties of concrete in order to make a prognosis of durability (RILEM REPORT 12,1995).

Despite the existence of numerous gas permeability test methods, there is still a lack of general agreement in standardizing. Gas permeability test methods are destructive and suitable primarily under laboratory conditions. In most cases, they require the conditioning of the test specimens before testing and, therefore, test results do not represent the actual situation. For instance, drying concrete in an oven at a temperature of over $100^{\circ} \mathrm{C}$ results in micro-cracks, while complete saturation results in changes in the pore structure of the testing specimens, due to possible rehydration. Therefore, it is difficult to compare the gas permeability of concrete if not given adequate attention. Instead of test specimen conditioning, the best alternative should be to assess or determine the moisture content of test specimen conditioning just before gas permeability testing, for instance by measuring the relative humidity in the cover concrete and considering the measured relative humidity value in the analysis of gas permeability coefficients. If proper relative humidity measurement methods are incorporated such steps are believed to reduce the effort involved in conditioning specimens in the laboratory and to give the actual material property (Dinku \& Reinhardt, 1997).

One of the recent diagnostic methods evaluating the actual state of covercrete porous structure is the air permeability method by Dr. Torrent. The method enables one to quantify the state of covercrete porous structure (into 30-50mm depth) so that from the measured values of the vacuum, which was formed in this covercrete, one can calculate a value of the coefficient of the air permeability $k_{T}$ and the depth of the vacuum action $L$. Based on the extensive measurements with TPT (Torrent Permeability Tester), both in a laboratory and "in situ", an author of the testing devices has set a five-degree scale enabling the sorting of the tests of concrete, from a durability viewpoint, into five individual classes from the design values $k_{T}$ (Torrent, 1992), (Torrent \& Frenzen, 1995)

\section{THE POSSIBILITIES OF CONCRETE COVER LAYER (COVERCRETE) PERMEABILITY REDUCTION}

The deterioration of concrete begins almost after casting, as the hardened properties are influenced by effects which occur at an early stage, such as plastic crashing, segregation and thermal events. Modern design and construction practice has led to improvements. There are two principle methods for improving the covercrete porous structure from the point of view of its impermeability. At first, the addition of different admixtures and ingredients into fresh concrete, and second, to implement the changes in production technology leading to a better quality of concrete from the durability viewpoint. From the admixtures that can modify the porous system of covercrete it is possible to apply silica fume, fly ashes, blast furnace slag, and very fine stone dust. As an admixture, soft polypropylene low modular fibers and high-strength fibers for the spatial reinforcing of concrete can also be considered. The purpose of the application of all admixtures is to reduce the development of cracks in every stage of concrete setting and hardening. The admixtures of hydraulic or hiddenhydraulic character fill the gaps of aggregates used and compress a space on the interface of cement stone and aggregate grain.

The next method for decreasing covercrete permeability is the change of manufacturing technology of concrete. It consists of the selection of cement, design of optimal composition of fresh concrete, and subsequent manufacturing technology and in the placing and curing of fresh concrete. All changes have to be carried out so as to eliminate crack development due to hydration, heat, plastic settlement, and shrinkage in the phase of concrete setting 
and hardening, and small cracks caused by gas welding. The cracks originate due to the action of chemical shrinkage and internal drying. Another source of covercrete permeability decreasing are the cracks caused by concrete drying.

The processes leading to the limitation of the development of cracks in a covercrete consist of the selection of cement with a low hydration heat, in restriction of the hydration heat effects, e.g. by overnight casting, in the selection of high-quality aggregates without clay admixture, in the optimal design of fresh concrete composition, in the reduction of water coefficient at attaining the required workability of fresh concrete. Concrete should be placed into quality form work equipped with special covering drainage textiles that reduce the value v/c. Casting in large volumes should be also reduced and the fresh setting of concrete should be treated with water in the course of its maturation. Optionally, it is possible to apply some impervious coating or protective foil for hardening concrete [5] [6]. (Adámek \& Juránková, 2003), (Adámek \& Juránková, 2003).

\section{TORRENT PERMEABILITY TESTER (TPT)}

The Torrent permeability tester (TPT) produced by a Swiss company, Proceq, was used for experimental tests on the air permeability of building materials' surface layers, especially that of concrete. The TPT is a modern device, which is applicable for the non-destructive determination of the covercrete air permeability. The device works together with a vacuum pump. The basic parts of the device are two chambered vacuum cells and a pressure regulator that regulates the air flowing into the internal chamber located perpendicular to the concrete surface. Further components of the measuring device are the vacuum pump, regulating unit, and an indicator with an LC display permitting data recording for up to 200 measurements.

The vacuum cell is fixed on the measured area and the vacuum pump is turned on. After about one minute the required vacuum level is reached and the vacuum from the pump works from this moment in the external chamber only in order to balance the pressure in the internal and external chambers. Thus, the air acting around the internal chamber compass prevents an increasing of the pressure in the internal chamber. The indicator records the pressure increasing inside the internal chamber by the air passing through a surface layer into the internal chamber. The air permeability factor of a cylindrical concrete tubus below the internal chamber is derived from Poisseuille`s relation as

$$
\frac{d V}{d t}=\frac{k A\left(P_{a}^{2}-P_{I}^{2}\right)}{2 \mu L P_{I}}
$$

where:

$V \quad$ is volume of air penetrating into the internal chamber in the course of time $d t$

$k \quad$ is air permeability factor $\left(\mathrm{m}^{2}\right)$

$P_{a} \quad$ is atmospheric pressure $\left(\mathrm{Nm}^{-2}\right)$

$P_{I} \quad$ is pressure inside the internal chamber $\left(\mathrm{Nm}^{-2}\right)$

A is cross-sectional area of the internal chamber $\left(\mathrm{m}^{-2}\right)$

$\mu \quad$ is dynamic viscosity of air $\left(\mathrm{Nsm}^{-2}\right)$ 
Effective depth $L(t)$ in time $t$ is a depth in which the air inside the pores reached the atmospheric pressure $P_{a}$. The pressure changes linearly which the depth. By inserting a set of hypothesis into the relation (1), we obtain the definite relation for permeability factor calculation $k_{T}$

$$
k_{T}=4\left[\frac{V_{c}\left(d P_{I} / d t\right)}{A\left(P_{a}^{2}-P_{I}^{2}\right)}\right]^{2} \frac{\mu P_{a}}{\varepsilon} \int_{t_{o}}^{t}\left[1-\left(\frac{P_{I}}{P_{a}}\right)^{2}\right] d t
$$

where:

$V_{c} \quad$ is volume of the internal chamber and body through which the air flows $\left(\mathrm{m}^{3}\right)$

$\varepsilon \quad$ is open porosity of concrete $\left(\mathrm{m}^{3} \mathrm{~m}^{-3}\right)$ and

$d P_{1} / d t$ is derivation of pressure with time $t\left(\mathrm{Nm}^{-2} \mathrm{~s}^{-1}\right)$

The calculation of both constants $k_{T}$ a $L$ is performed with numeric integration and derivation with software of the indicator. The problem is the determination of the constant $\varepsilon$ - open porosity of concrete, which is different for various concretes. This constant is either estimated or determined by tests. For the air permeability factor $k_{T}$ calculations with the TPT mean value of the open porosity $\varepsilon=0.15$, that was evaluated by the author of the TPT from the extensive sets of tests, were used (Torrent, 1992).

\section{EVALUATION OF CONCRETES FROM THE POINT OF DURABILITY}

Based on the extensive experimental research of the author of the device (Torrent, 1992), both in laboratory and in situ, criteria were determined for the evaluation of concrete durability. Classification of the covercrete quality is specified in 5 classes (Table 1). To every quality class a range of values of the permeability factor is assigned determined by the concrete after 28 days aging.

Table 1: Classification of the Quality of the “Covercrete” according to $\mathbf{k}_{\mathbf{T}}$.

\begin{tabular}{|l|l|l|}
\hline \multicolumn{2}{|l|}{ Clasification of the covercrete quality } & $k_{T}$ measured at 28 days $\left[\mathrm{E}^{-16} \mathrm{~m}^{2}\right]$ \\
\hline 1 & very good & $k_{T}<0,01$ \\
\hline 2 & good & $0,01<k_{T}<0,1$ \\
\hline 3 & normal & $0,1<k_{T}<1,0$ \\
\hline 4 & bad & $1,0<k_{T}<10$ \\
\hline 5 & very bad & $k_{T}>10$ \\
\hline
\end{tabular}

The permeability factors $k_{T}$ are valid for dry matured concretes. When concretes are wet, or there are doubts whether they are dry or wet, the Wenners four points probe, that measures 
electric resistance $\rho[\mathrm{k}$ ohm $\mathrm{cm}]$, is used. The value of resistance $\rho$ is measured prior to the determination of the permeability factor $k_{T}$, or optionally the mean value $\rho$ is inserted into the indicator manually. The amount of water or vapor in a porous structure of concrete significantly influences the concrete's extent of permeability. The more wet the concrete is, the less is its permeability, and it appears to be of high performance from the viewpoint of durability. After water has evaporated from the pores, the permeability value increases and concrete is more permeable.

\section{EXPERIMENTAL WORKS}

\subsection{Silica fumes as an admixture into concrete}

We tested the influence of powder silica Sioxid and micro-silica in a water suspension Elkem on the values of the coefficient of permeability to air $k_{T}$. The compared reference without silica was measured, (R). The doses were identical for both types of admixture, 5 and $10 \%$, from the weight of cement (B-E).

The admixtures in both doses have an impact on the bending strength. The increase was about $17 \%$ higher. The compressive strength of concrete was almost the same. The comparison of permeability coefficient $\mathrm{k}_{\mathrm{T}}$ in all concretes in relation to moisture is shown in Figure1.

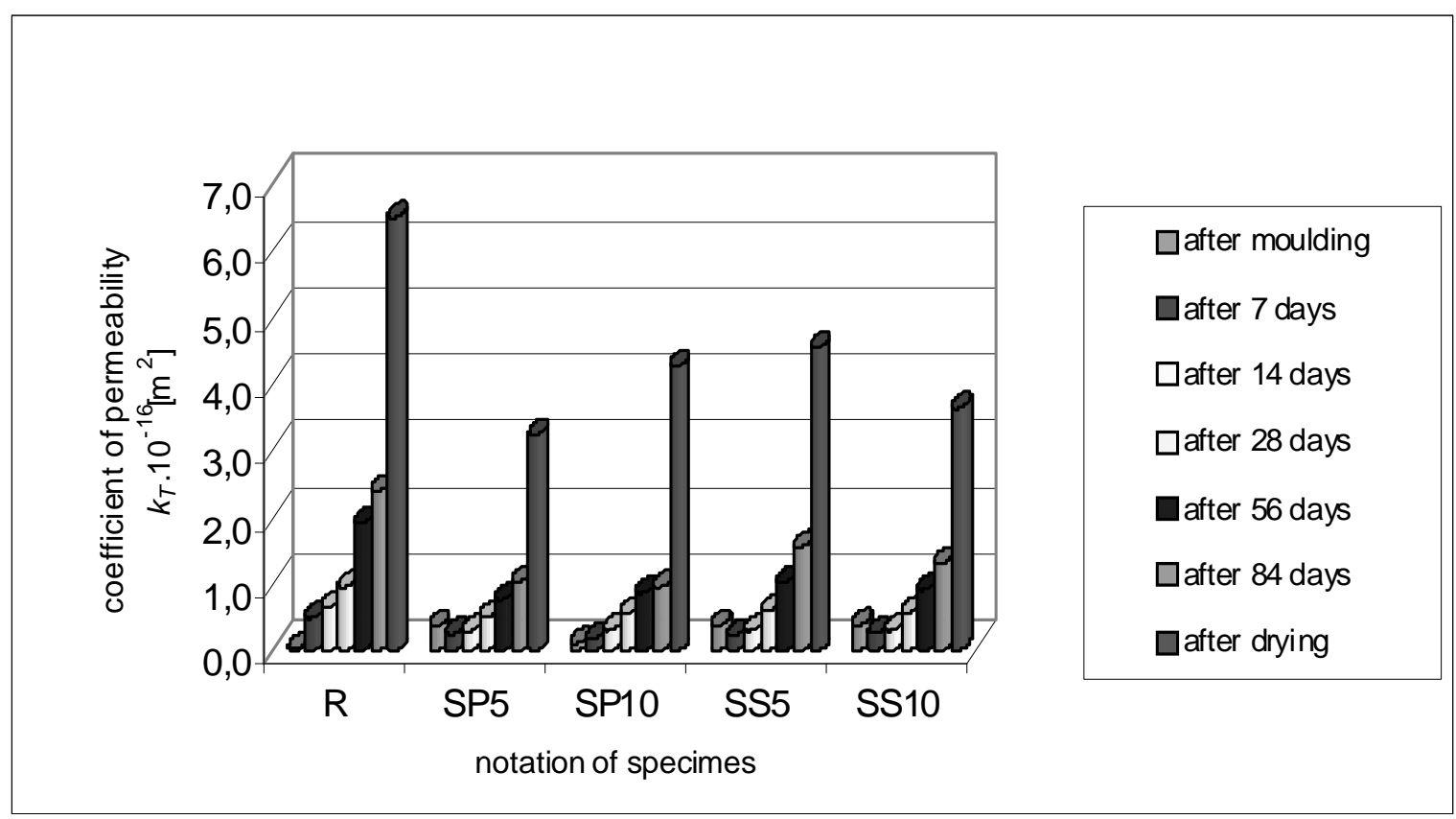

Figure 1: The relation of permeability coefficients on aging in silica concrete fume.

\subsection{Fly ash as a part replacement of fine aggregate}

Fly ashes and blast furnace slag performed similarly as silica fumes. Both materials create a soft part of fresh concrete and improve its plasticity, compress the contact zone 
among the aggregate grains and matured cement. Hydraulicity of both components contributes, not only to the "sealing" of a concrete structure, but especially to the tensile and compressive strength enlargement. Last, but not least, they contribute to the decreasing of the concrete's permeability to liquids and gases, and thus to the improvement of covercrete property in the durability viewpoint.

\subsection{Fibers as reinforcement for cracks reduction}

Polymer soft fibers were dosed into fresh concrete in a volume of 0.6 and $0.9 \mathrm{~kg} / \mathrm{m}^{3}$ in accordance with the producers' recommendations. The basic properties of 4 different concretes with PP fibers (B-E) and comparative concrete without fibers (A) were verified. Even though it was not assumed that these soft fibers would contribute to strength improvement, the bending strengths tested at ages 7, 28 and 84 days were on average about $13.5 \%$ higher than comparative concrete. The effect of the improved state of covercretes with fibers (in Figure 2 and 3 marked B-E) reveal curves expressing the influence of the values of the coefficient of permeability for air $k_{T}$ on the aging period and on the moisture of tested concretes. In both cases the values $k_{T}$ of concrete B-E were lower than ones of comparative concrete. The water content in the porous layer of the tested concretes principally influences the real values of permeability.

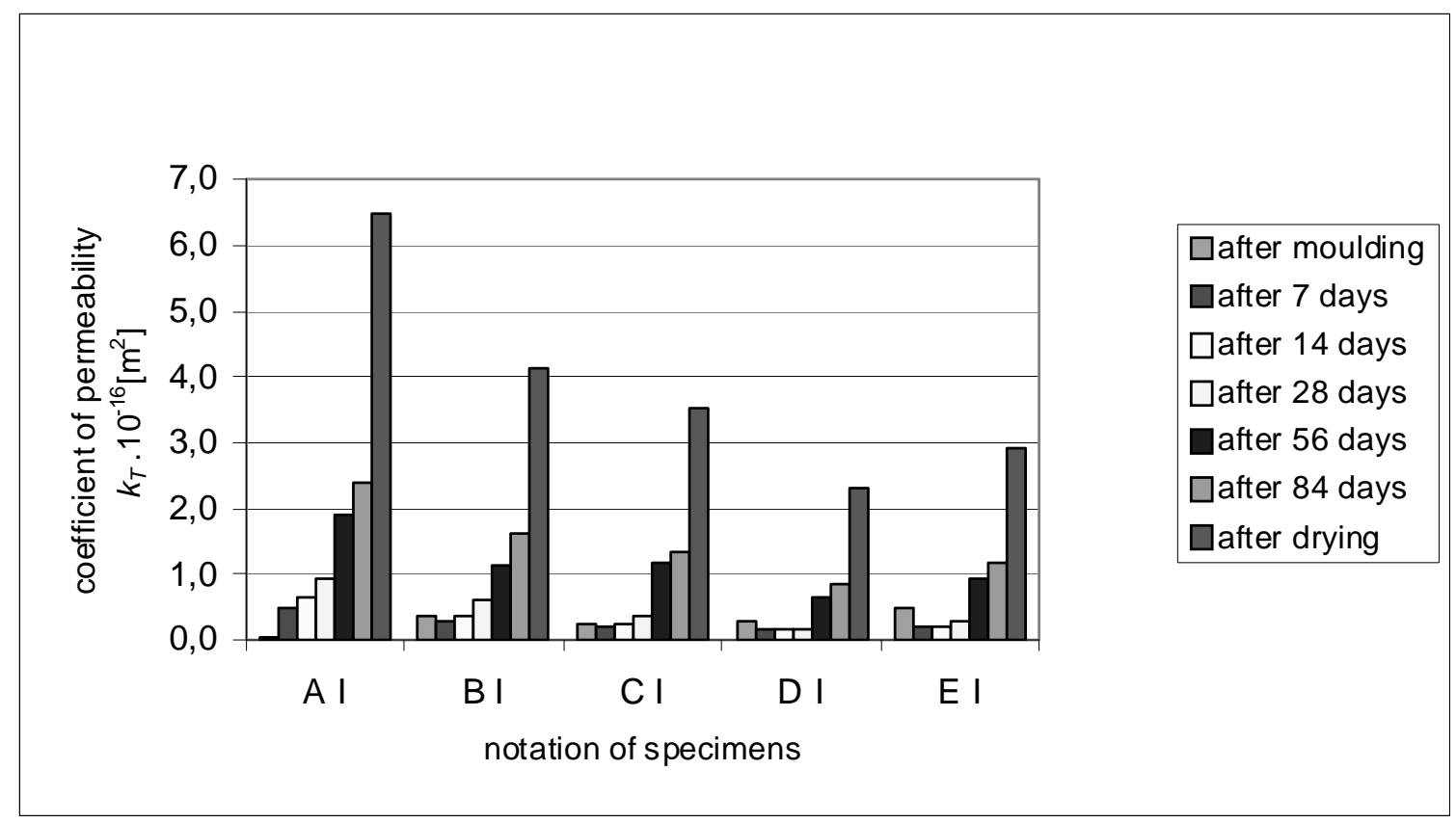

Figure 2: Coefficient of permeability $\mathbf{k}_{\mathrm{T}}$ in relation to aging time in concrete with soft fibers. 


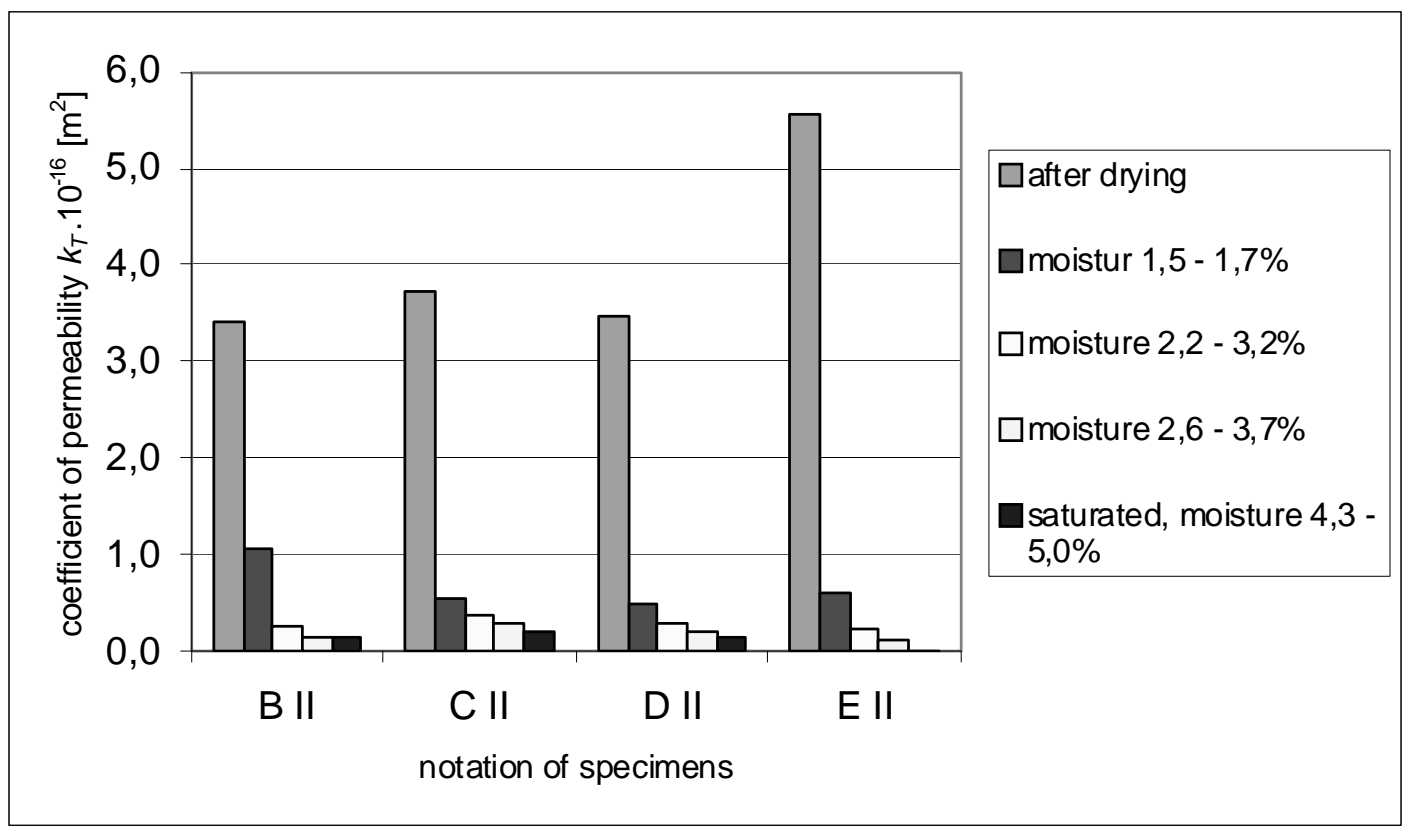

Figure 3: The relations of permeability coefficients and moisture content in concrete with soft fibers

\section{CONCLUSION}

The objective of this contribution was a recapitulation of the possibilities of covercrete impermeability improvement and, by that, to specify the procedures on how to reduce an intrusion of aggressive gaseous and liquid media into concrete. The methods consist of the design of concrete mixtures, or in the change of the manufacturing technology of concrete, and demonstrate in a different way the properties improvement of hardening concrete in relation to its durability.

\section{ACKNOWLEDGMENT.}

This paper presents results of research supported by the project of GAČR 103/09/0065 and project VVZ MSM 0021630511.

\section{REFERENCES}

Adámek,J., Juránková, V.,2003 Permeability of Concrete with PP-Fibres, Int. Symposium F. bre Concrete and High-performance Concrete, Malenovice, Czech Republic, pp. 136-143.

Adámek,J., Juránková,V.,2003, Air Permeability of Concrete, IV. Konferencija Naukowo Techniczno, Zagadnenia Materialowe w Inžynierii Ladowei, Krakow, Polsko, pp.43-49. 
Dinku,A., Reinhardt,H.W, 1997, Gas Coefficient of Cover Concrete as a Performance Control, Materials and Structures, Vol.30, pp.387-393.

RILEM Report 12, 1995, Performance Criteria for Concrete Durability, TC 116-PCD, Performance of Concrete as a Criterion of its Durability, Ed. Kropp,J., Hilsdorf, H.K, 1995 (E+FN Spon).

Torrent,R.J., 1992, A two-Chambers Vacuum Cell for Measuring the Coefficient of Permeability to Air of the Concrete Cover in Site, Materials and Structures, vol.25, pp.358-365.

Torrent,R.J., Frenzer,G.,1995, A method for the rapid determination of the coefficient of permeability of the "covercrete", Int. Symposium Non-destructive Testing in Civil Engineering (NDT-CE), Berlin, p.985-992. 